\title{
On the Study of Sorption in the Chiral Separation of the Enantiomers of Salbutamol and Salmeterol by Supercritical Fluid Chromatography
}

\author{
Irina V. Mikushina*a, \\ Natalya G. Bazarnova ${ }^{a}$, Olga O. Parenago ${ }^{b}$, \\ Konstantin V. Gensh ${ }^{\mathrm{a}}$ and Marina Yu. Cheprasova ${ }^{\mathrm{a}}$ \\ ${ }^{a}$ Altay State University \\ 61 Lenin, Barnaul, 656049, Russia \\ ${ }^{b}$ Institute of General and Inorganic Chemistry N.S. Kurnakova \\ 31 Leninsky Prospect, Moscow,119071, Russia
}

Received 26.06.2019, received in revised form 11.07.2019, accepted 04.08.2019

The studied conditions of supercritical fluid chiral chromatography of salbutamol and salbutamol sulfate allowed to assumethe possibility of ionic interactions in the process of separation of enantiomers. It is shown that the structure of the hydrocarbon radical of 1- (4-hydroxy-3- (hydroxymethyl) phenyl) -2-aminoethanol associated with the chiral fragment, and, consequently, the physicochemical characteristics of the substance molecule, such as the number of hydrogen donors and acceptors polar surface, significantly affect the ability to communicate with the sorbent selectors under conditions of supercritical fluid chromatography.

Keywords: enantiomers, supercritical fluid chromatography, chiral separation, sorption mechanism, salbutamol, salmeterol.

Citation: Mikushina I.V., Bazarnova N.G., Parenago O.O., Gensh K.V., Cheprasova M.Yu. On the study of sorption in the chiral separation of the enantiomers of salbutamol and salmeterol by supercritical fluid chromatography, J. Sib. Fed. Univ. Chem., 2019, 12(3), 310-318. DOI: 10.17516/1998-2836-0128.

(C) Siberian Federal University. All rights reserved

* Corresponding author E-mail address: mikuschinai@mail.ru 


\title{
К вопросу об изучении сорбции
}

\section{при хиральном разделении энантиомеров сальбутамола \\ и сальметерола методом}

сверхкритической флюидной хроматографии

\author{
И.В. Микушина ${ }^{a}$ Н.Г. Базарнова ${ }^{a}$, \\ О.О. Паренаго ${ }^{\tilde{\sigma}}$, К.В. Геньш ${ }^{\mathrm{a}}$, М.Ю. Чепрасова ${ }^{\mathrm{a}}$ \\ алттайский государственный университет \\ Россия, 656049, Барнаул, пр. Ленина, 61 \\ ${ }^{6}$ Институт общей и неорганической химии им. Н.С. Курнакова РАН \\ Россия, 119071, Москва, Ленинский пр., 31
}

Изученные условия сверхкритического флюидного хирального хроматографирования сальбутамола и сульфата сальбутамола позволили предположить возможность ионных взаимодействий в процессе разделения энантиомеров. Показано, что структура углеводородного радикала, связанного с хиральным фрагментом 1- (4-гидрокси-3- (гидроксиметил) фенил) -2 аминоэтанола, а следовательно, физико-химические характеристики молекуль вещества, такие как количество доноров и акиепторов водорода и площадь топологической полярной поверхности, существенно влияют на способность связываться с селекторами сорбента в условиях сверхкритического флюидного хроматографирования.

Ключевые слова: энантиомеры, сверхкритическая флюидная хроматография, хиральное разделение, механизм сорбиии, сальбутамол, сальметерол.

\section{Введение}

В настоящее время растет потребность в быстрых и эффективных способах хирального разделения в аналитическом и препаративном масштабе фармацевтических субстанций, имеющих оптические изомеры, отличающиеся физиологической активностью. Несмотря на существенный пул публикаций по хиральному разделению фармацевтических субстанций методами хроматографии, отсутствует однозначная адекватная модель сорбционных процессов [1], а появление все большего количества хиральных сорбентов с селекторами различной природы [2], с одной стороны, позволяет осуществить энантиоразделение многих классов оптически активных соединений, с другой - не решает задачу пониманияи прогнозирования механизмов процесса хирального разделения энантиомеров. Тем не менее при хиральном хроматографическом разделении энантиомеров исследователи отмечают наличие как неспецифических (гидрофобных) взаимодействий (молекулярная адсорбция), так и специфических взаимодействий (водородные связи, диполь-дипольные взаимодействия, ионообменные, донорно-акцепторные, $\pi$ - $\pi$-взаимодействия), которые определяются типом сорбента, природой селекторов, а также составом подвижной фазы и условиями хроматографирования [3, 4]. 


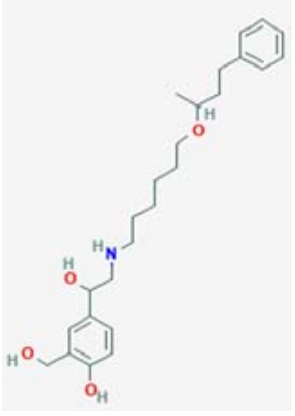

1-(4-гидрокси-3-(гидроксиметил)фенил)-2((6-(1-метил-3-фенилпропокси)гексил)амино) этанол - сальметерол

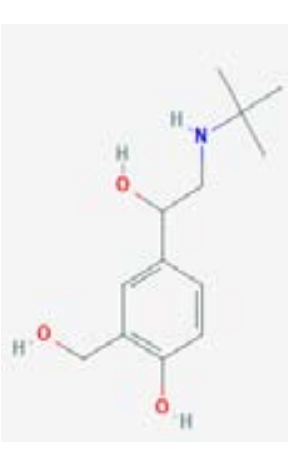

4-[2-(трет-бутиламино)-1-гидроксиэтил]-2(гидроксиметил)фенол - сальбутамол

Рис. 1. Структурные формулы b2-блокаторов адренорецепторов

Fig. 1. Structural formulas of b2-blockers of adrenoreceptors

Современные исследования терапевтической активности фармацевтических субстанций позволяют однозначно говорить о специфическом биологическом взаимодействии отдельных энантиомеров с рецепторами [5]. Агонисты b2-адренорецептора, такие как сальбутамол и сальметерол (структурные формулы приведены на рис. 1), используются в симптоматическом лечении астмы и хронического бронхита, представлены в лекарственных препаратах, как правило, в виде рацемической смеси R- и S-изомеров.

Однако в ряде публикаций $[6,7]$ показано, что нужной физиологической активностью обладает только один энантиомер. Аналитическое разделение изомеров сальбутамола и сальметерола может быть достигнуто методами электрофореза, тонкослойной и жидкостной хроматографии, прежде всего ВЭЖХ [8]. Как правило, применение методов ВЭЖХ сопряжено с использованием смесей органических растворителей в качестве подвижной жидкой фазы, а также требуется внесение модификаторов для обеспечения эффективного разделения энантиомеров [9, 10]. Ряд проблем энантиомерного разделения b2-блокаторов может быть решено методами «зеленой химии»: сверхкритической флюидной хроматографией.

Целью настоящей работы являлся поиск возможных сорбционных механизмов при энантиомерном разделении рацемических смесей b2-блокаторов адренорецепторов.

\section{Экспериментальная часть}

Хиральное разделение b2-блокаторов адренорецепторов осуществляли на полупрепаративном сверхкритическом флюидном хроматографе, модель Investigator SFC System производства компании Waters Corp, США, с хиральной аналитической колонкой с сорбентом, модифицированным хиральным селектором на основе иммобилизованной трис-(3-хлор-5метилфенилкарбамат)амилозы (IG) Chiralpak IG 150x4.6; 5 мкм. Разделение проводили при скорости потока 4 мл/мин, массовой доле сорастворителя (метанола) в подвижной фазе $15 \%$, давление 120 бар. Температура разделения $35^{\circ} \mathrm{C}$. Длина волны детектирования 225 нм для сальбутамола и 217 нм для сальметерола. 


\section{Результаты и их обсуждение}

В обзоре [11] показана принципиальная возможность разделения энантиомеров 1,2-аминоспиртов, к которым могут быть отнесены b2-адренергические агонисты сальбутамол и сальметерол, с помощью методов сверхкритической флюидной хроматографии, которые обеспечивают достаточную селективность и способствуют получению чистых энантиомеров при использовании меньшего числа органических растворителей.

Нами на приборе Investigator SFC System (США) с хиральной хроматографической колонкой на основе иммобилизованной трис-(3-хлор-5-метилфенилкарбамат)амилозы (IG) проведено разделение сальбутамола (в виде основания) при использовании триэтиламина в качестве динамического модификатора и без него (рис. 2 и 3). В аналогичных условиях при разделении

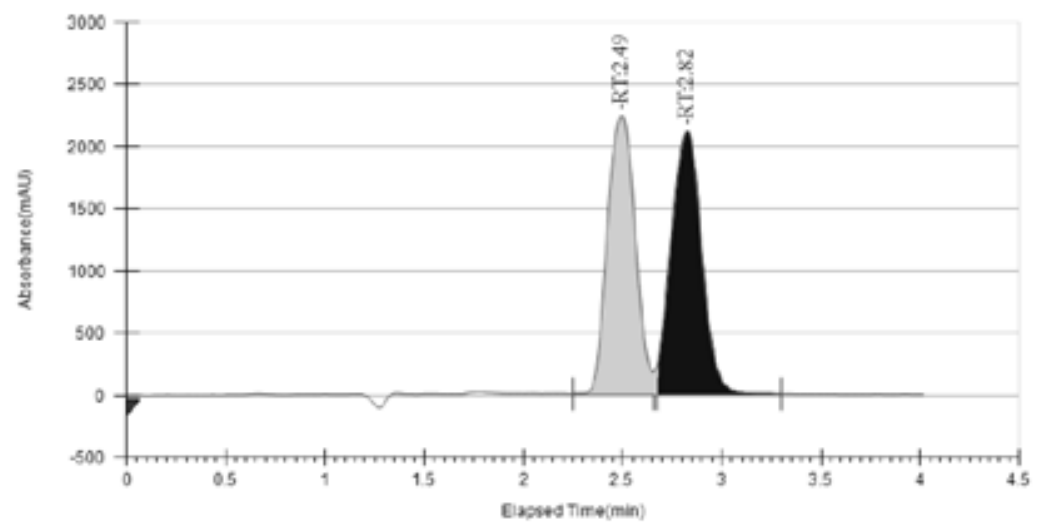

Рис. 2. Хроматограмма энантиомеров сальбутамола (колонка ChiralpakIG, сорастворитель метанол, динамический модификатор триэтиламин - 0,5 объемных \%, давление 120 бар, температура колонки $35^{\circ} \mathrm{C}$, скорость потока 4 мл/мин, объем вводимой пробы аналита 5 мкл)

Fig. 2. Chromatogram of salbutamol enantiomers (Chiralpak IG column, methanol co-solvent, triethylamine dynamic modifier -0.5 volume $\%$, pressure $120 \mathrm{bar}$, column temperature $35^{\circ} \mathrm{C}$, flow rate of analyte $5 \mu \mathrm{l}$ )

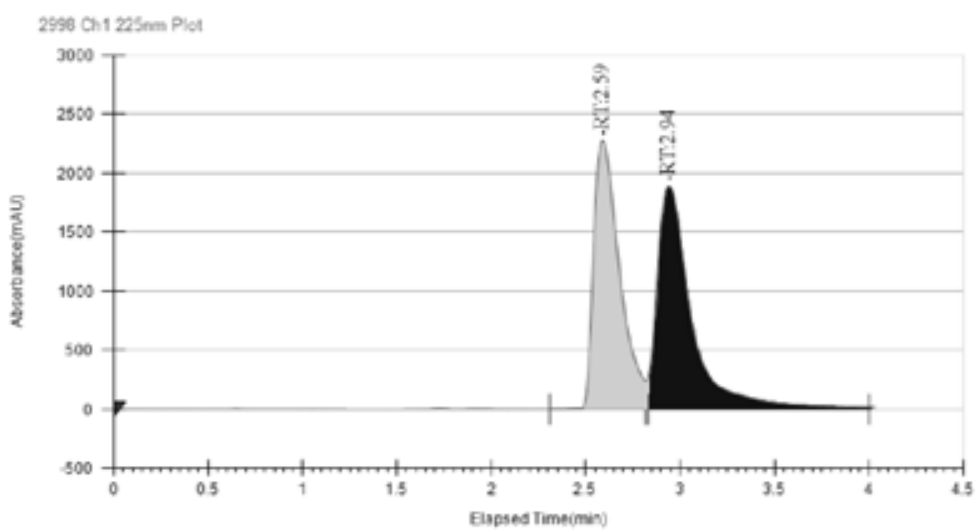

Рис. 3. Хроматограмма энантиомеров сальбутамола (колонка Chiralpak IG, сорастворитель метанол, давление 120 бар, температура колонки $35^{\circ} \mathrm{C}$, скорость потока 4 мл/мин, объем вводимой пробы аналита 10 мкл)

Fig. 3. Chromatogram of salbutamol enantiomers (Chiralpak IG column, methanol co-solvent, pressure $120 \mathrm{bar}$, column temperature $35^{\circ} \mathrm{C}$, flow rate $4 \mathrm{ml} / \mathrm{min}$, analyte injected sample volume $10 \mu \mathrm{l}$ ) 


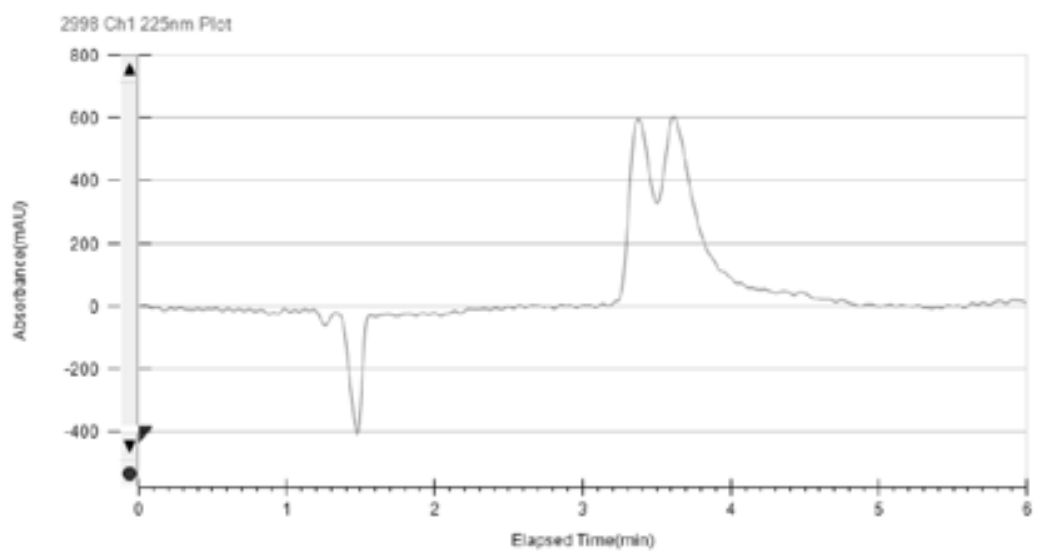

Рис. 4. Хроматограмма энантиомеров сальбутамола в форме сульфата (колонка ChiralpakIG, сорастворитель метанол, динамический модификатор триэтиламин, давление 120 бар, температура колонки $35^{\circ} \mathrm{C}$, скорость потока 4 мл/мин, объем вводимой пробы аналита 10 мкл)

Fig. 4. Chromatogram of enantiomers of salbutamol in the form of sulfate (Chiralpak IG column, co-solvent methanol, dynamic modifier triethylamine, pressure 120 bar, column temperature $35{ }^{\circ} \mathrm{C}$, flow rate of analyte $4 \mathrm{ml} / \mathrm{min} 10 \mu \mathrm{l})$

сальбутамола сульфата хроматограмма имеет недостаточно разрешенные пики с асимметричным уширением (рис. 4).

Селекторы данного сорбента содержат в своем составе карбоксилатную группу, вторичную аминную группу и ароматическое кольцо с донорным и акцепторным заместителем, что наряду с молекулярной адсорбцией может сопровождаться специфическими взаимодействиями в процессе сорбции (водородные связи, диполь-дипольные взаимодействия, ионообменные, донорно-акцепторные, $\pi$ - $\pi$-взаимодействия). Сальбутамол, по данным [12], имеет 4 донора и 4 акцептора водорода при образовании водородных связей, а площадь топологической полярной поверхности составляет $72,7 \mathrm{~A}^{2}$.

Как следует из рис. 2 и 3 , динамический модификатор триэтиламин способствует большей селективности разделения и повышению симметричности пиков хроматограммы. При исследовании влияния концентрации динамического модификатора на результативность энантиомерного разделения установлено, что увеличение объемной доли динамического модификатора от 0,1 до $0,5 \%$ способствует повышению качественных характеристик хроматограмм, а дальнейшее увеличение концентрации модификатора не приводит к их улучшению. Таким образом, можно предположить, что триэтиламин в составе подвижной фазы обеспечивает более эффективный процесс десорбции, вытесняя сорбат с поверхности сорбента за счет донорноакцепторных взаимодействий.

Ионизированная форма сульфата сальбутамола характеризуется большими значениями времен удерживания (рис. 4), вероятно, изменяются возможности специфических взаимодействий с селекторами сорбента (ионные взаимодействия), что и приводит к коэлюированию энантиомеров. Авторы исследования энантиоселективного разделения энаниомеров b-блокаторов методом ВЭЖX [10] предположили, что основную роль в энантиораспознавании играют электростатические взаимодействия между карбоксильными группами антибиотиков 
и атомами азота в структуре b-блокаторов. Ион триэтиламмония вступает в конкурирующие взаимодействия с карбоксильными группами селектора и влияет на энантиоселективность в сторону ее уменьшения. Полученные нами результаты позволяют полагать, что, вероятно, в системе сальбутамол сульфат-триэтиламин происходит также образование иона триэтиламмония в связи с более выраженными основными свойствами триэтиламина по сравнению с сальбутамолом, что приводит к наблюдаемому эффекту. Данное предположение косвенно подтверждается результатами, описанными авторами [13]. Ими показано, что при использовании сорбента с хиральным селектором на основе макроциклического гликопептида эремомицина возможно селективное разделение энантиомеров сульфата сальбутамола с помощью сверхкритической флюидной хроматографии при использовании одновременно двух динамических модификаторов: изопропиламина и трифторуксусной кислоты либо амина и аммониевой соли. При этом указывается, что мольная концентрация амина в составе подвижной фазы должна быть выше мольной концентрации кислоты, в противном случае не происходит разделение энантиомеров. Отмечена возможность ионных взаимодействий между сорбентом и аналитом в условиях сверхкритической флюидной хроматографии аналогичных, реализуемых в ВЭЖХ.

Структурная формула сальметерола (рис. 1) имеет в своем составе аналогичный сальбутамолу фрагмент 1,2-аминоспиртов с хиральным центром. В связи с этим предположили, что в аналогичных условиях может быть достигнуто разделение энантиомеров сальметерола в форме основания или в форме соли ксенофоата (фармацевтическая субстанция) (рис. 5 и 6).

Однако физико-химические характеристики сальметерола (по данным [12], сальметерол имеет 4 донора и 5 акцепторов водорода при образовании водородных связей, а площадь топологической полярной поверхности составляет 82,0 $\mathrm{A}^{2}$ ) существенно отличаются от таковых сальбутамола за счет структуры углеводородного радикала, связанного с 1- (4-гидрокси-3- (гидроксиметил) фенил) -2 - аминоэтанолом. Полученные хроматограммы позволили зафиксиро-

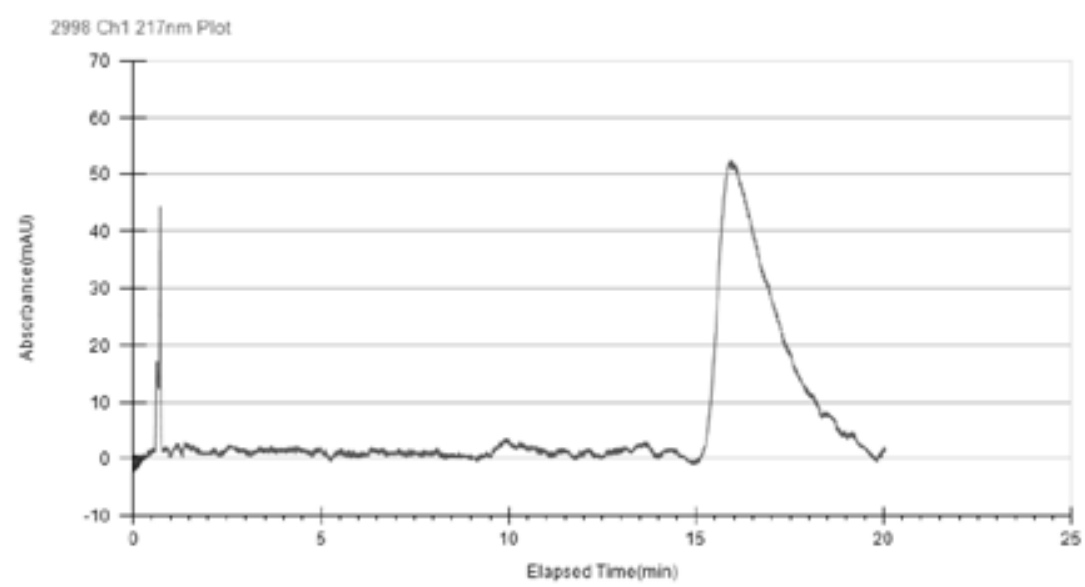

Рис. 5. Хроматограмма сальметерола (сорастворитель метанол, динамический модификатор триэтиламин, давление 120 бар, температура колонки $35^{\circ} \mathrm{C}$, скорость потока 4 мл/мин, объем вводимой пробы аналита 10 мкл)

Fig. 5. Chromatogram of salmeterol (co-solvent methanol, dynamic modifier triethylamine, pressure 120 bar, column temperature $35^{\circ} \mathrm{C}$, flow rate $4 \mathrm{ml} / \mathrm{min}$, analyte sample intake volume $10 \mu \mathrm{l}$ ) 


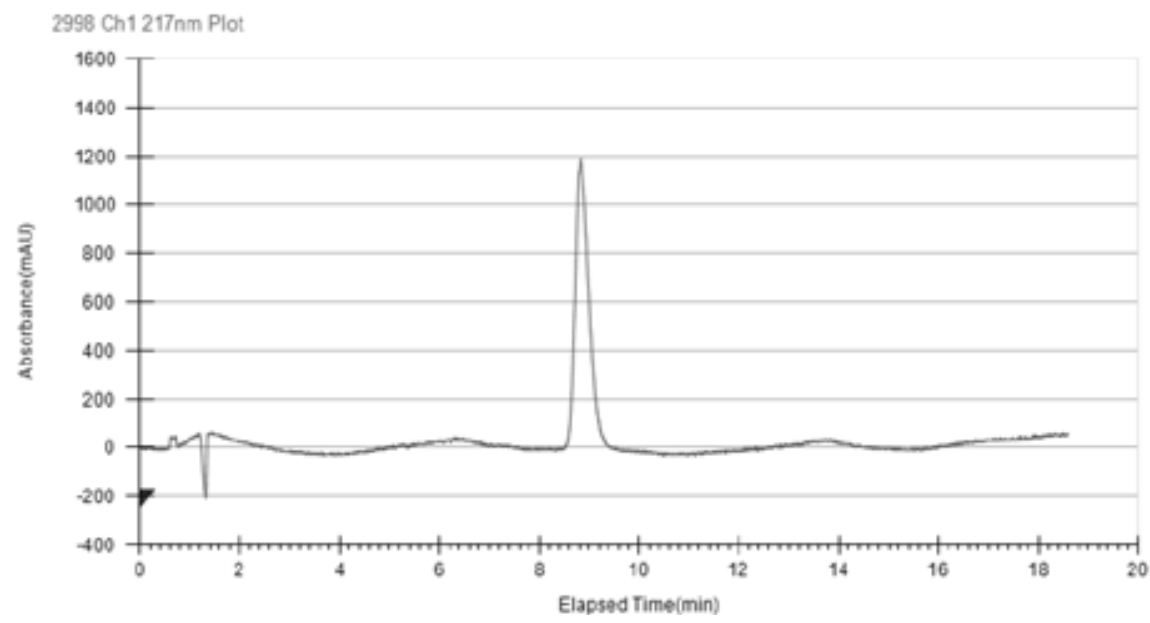

Рис. 6. Хроматограмма сальметерола ксенофоата (сорастворитель метанол, динамический модификатор триэтиламин, давление 120 бар, температура колонки $35^{\circ} \mathrm{C}$, скорость потока 4 мл/мин, объем вводимой пробы аналита был равен 10 мкл)

Fig. 6. Chromatogram of salmeterol xenophoate (co-solvent methanol, dynamic modifier triethylamine, pressure $120 \mathrm{bar}$, column temperature $35^{\circ} \mathrm{C}$, flow rate $4 \mathrm{ml} / \mathrm{min}$, the amount of analyte sample injected was $\left.10 \mu \mathrm{l}\right)$

вать время удерживания, характерное для сальметерола и сальметерола ксенофоата в условиях сверхкритического флюидного хроматографирования. Установлено, что эти характеристики и особенности структуры в целом способствуют увеличению времен удерживания сальметерола основания по сравнению с сальбутамолом. Следовательно, в данных условиях сальметерол более прочно связывается с селекторами сорбента за счет больших возможностей для полярных взаимодействий. Однако хроматограмма ксенофоата сальметерола характеризуется уменьшением времени удерживания по сравнению с формой основания, в то время как сульфат сальбутамола имеет большее время удерживания, чем основание сальбутамола. Возможно, это связано с тем, что 1-гидрокси-2-нафтилкарбоновая кислота за счет ароматической природы экранирует активные центры молекулы сальметерола и, таким образом, снижается возможность связывания активных центров сорбата с селекторами сорбента, что не реализуется в молекулах сальбутамола сульфата, в котором происходит более прочное связывание за счет ионных взаимодействий.

\section{Заключение}

Таким образом, показано влияние специфических взаимодействий на возможность энантиомерного разделения b2-адренергических агонистов сальбутамола и сальметерола. Проведено энантиомерное разделение сальбутамола методом сверхкритической флюидной хроматографии с использованием триэтиламина в качестве динамического модификатора и метанола в качестве сорастворителя на хиральной колонке Chiralpak IG, сделаны некоторые предположения о механизме сорбции. Изученные условия хроматографирования позволили выявить время удерживания сальметерола и ксенофоата сальметерола, что служит необходимым условием в поиске и разработке оптимальных условий селективного разделения энантиомеров методом сверхкритической флюидной хроматографии.

$$
-316-
$$




\section{Работа выполнена при поддержке гранта РФФИ №18-29-06033мк.}

\section{Список литературы}

1. Asnin L. Adsorption models in chiral chromatography Journal of Chromatography A 2012. Vol. 1269, P. 3-25.

2. Федорова И.А., Шаповалова Е.Н., Шпигун О.А. Смешанные хиральные неподвижные фазы в хроматографии (обзор) Сорбционные и хроматографические процессы 2018. Т. 18 (5), C.618-630 [Fedorova I.A., Shapovalova E.N., Shpigun O.A. Mixed chiral stationary phases in chromatography (review) Sorption and chromatographic processes. 2018. Vol. 18 (5), P. 618-630 (In Russ.)]

3. Kuznetsov M.A., Nesterenko P.N., Vasiyarov G.G. et al. High-performance liquid chromatography of $\alpha$-amino acid enantiomers on eremomycin-modified silica J. Anal. Chem. 2008. Vol. 63 (1), P. 57-64.

4. Решетова Е.Н., Аснин Л.Д., Качмарски К. Влияние вторичных равновесий при адсорбции энантиомеров ибупрофена на хиральной неподвижной фазе с привитым антибиотиком эритромицином. Журнал физической химии 2018. Т. 92 (2), C. 323-329 [Reshetova E.N., Asnin L.D., Kachmarsky K. Effect of secondary equilibria in adsorption of enantiomers of ibuprofen on the chiral stationary phase with antibiotic grafted erythromycin. Journal of Physical Chemistry 2018. Vol. 92(2), P. 323-329 (In Russ.)]

5. Burke D., Henderson J. Chirality: a blue print for the future BJA: British Journal of Anaesthesia 2002. Vol. 88 (4), P. 563-576.

6. Nials A. T., Coleman R. A., Johnson M., Vardey C. J. The beta adrenoceptor pharmacology of the enantiomers of salmeterol. Am. Rev. Respir. Dis. 1994. Vol. 149 (4), P. A481.

7. Penn R.B., Frielle T., McCullough J.R. et al. Comparison of $R$-, $S$-, and $R S$-albuterol interaction with human $\beta_{1}$ and $\beta_{2}$-adrenergic receptors. Clin. Rev. Allergy Immunol. 1996. Vol. 14 (1), P. 37.

8. Yang Y., Rosales-Conrado N., Guille'n-Casla V., Leo'n-Gonza'lez M.E., Pe'rez-Arribas L.V., Polo-Di'ez L.M. Chiral Determination of Salbutamol, Salmeterol and Atenolol by Two-Dimensional LC-LC: Application to Urine Samples. Chromatographia 2012. Vol.75(23-24), P. 1365-1375.

9. Jacobson G.A., Hostrup M., Narkowicz C.K., Nicholsd D.S.,Waltersa E.H. Enantioselective disposition of (R)-salmeterol and (S)-salmeterol in urine following inhaled dosing and application to doping control. Drug Test. Analysis 2017.Vol. 9(8), P. 1262-1266.

10. Федорова И. А. Индивидуальные и смешанные сорбенты на основе эремомицина для хиральной высокоэффективной жидкостной хроматографии: Дисс. ... канд. хим. наук. Москва, 2017. 181 c. [Fedorova I.A. Individual and mixed sorbents based on eremomycin for chiral highperformance liquid. Thesis for the degree of candidate of chemical sciences. Moscow, 2017. 181 p. (In Russ.)]

11. Геньш К.В., Геньш Т.С., Базарнова Н.Г. Хиральная сверхкритическая флюидная хроматография 1,2-аминоспиртов сальбутамола. Сверкритические флюиды: теория и практика. 2018. T. 13(3), C. $45-55$ [Gensh K.V., Gensh T.S., Bazarnova N.G. Chiral supercritical fluid chromatography of salbutamol 1,2-amino alcohols Supercritical fluids: theory and practice. 2018. Vol. 13(3), P. 45-55 (In Russ.)]

12. The PubChem Project: http://pubchem.ncbi.nlm.nih.gov 
13. Pokrovskiy O.I., Parenago O.O., Lunin V.V., Kayda A.S., Usovich O.I. Effect of additives on eremomycin sorbent selectivity in separation of salbutamol enantiomers using supercritical fluid chromatography. Russian Journal of Physical Chemistry A. 2017. Vol. 91(11), P. 2288-2290. 